This item was submitted to Loughborough's Research Repository by the author.

Items in Figshare are protected by copyright, with all rights reserved, unless otherwise indicated.

\title{
Work limitations and employer adjustments for employees with chronic
} illness

PLEASE CITE THE PUBLISHED VERSION

PUBLISHER

(C) Lippincott Williams \& Wilkins

VERSION

AM (Accepted Manuscript)

LICENCE

CC BY-NC-ND 4.0

\section{REPOSITORY RECORD}

Munir, Fehmidah, David Jones, Stavroula Leka, and Amanda Griffiths. 2019. "Work Limitations and Employer Adjustments for Employees with Chronic Illness”. figshare. https://hdl.handle.net/2134/4858. 
This item was submitted to Loughborough's Institutional Repository (https://dspace.lboro.ac.uk/) by the author and is made available under the following Creative Commons Licence conditions.

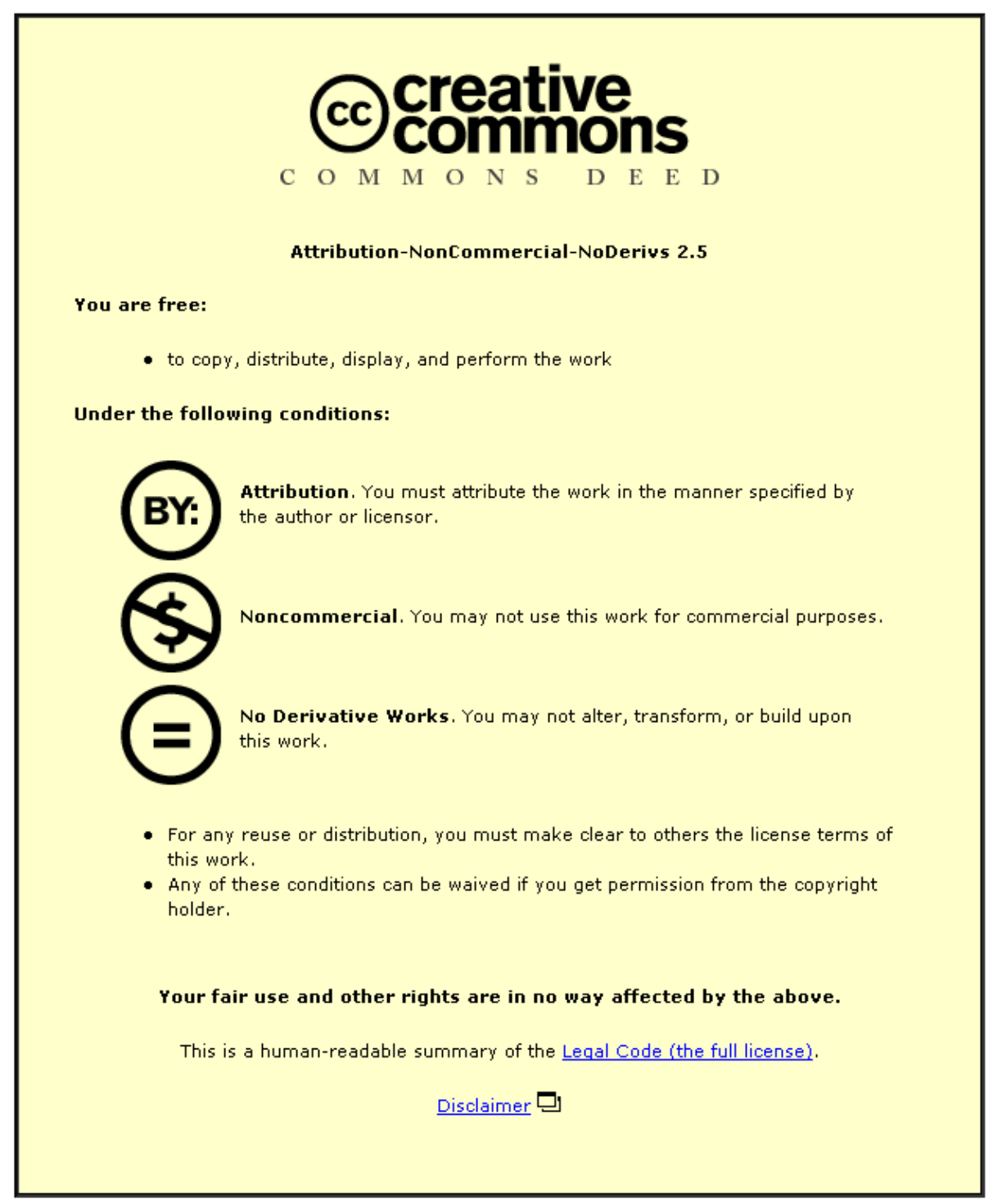

For the full text of this licence, please go to: http://creativecommons.org/licenses/by-nc-nd/2.5/ 
Work limitations and employer adjustments for employees with chronic illness.

\author{
*F. Munir, D. Jones, S. Leka, A. Griffiths
}

Published in: International Journal of Rehabilitation Research, 2005, 28; 111-117.

\author{
Institute of Work, Health \& Organisations, \\ University of Nottingham, \\ 8 William Lee Buildings \\ Nottingham Science \& Technology Park, \\ University Boulevard \\ Nottingham NG7 2RQ
}

Running title: work adjustments for chronically ill employees

Key words: employees, chronic illness, work adjustments, disclosure

*Corresponding author. Address as above. Email: fehmidah.munir@nottingham.ac.uk Tel: 0115846 6639. Fax: 01158466749 


\title{
Work limitations: Employer adjustments for employees with chronic illness.
}

\begin{abstract}
This study measured work limitations and work adjustments among chronically ill employees with regard to three distinct job characteristics: physical work demands, cognitive work demands and social work demands. The study presents findings from an organisational-based survey, of which 610 respondents reported managing employees with a chronic illness. These included arthritis, musculoskeletal pain, diabetes, asthma, migraine, heart disease, irritable bowel syndrome and depression. The results indicate that depression had the largest impact in all three work demand categories, while musculoskeletal pain principally affected physical work demands and migraine and diabetes largely affected cognitive work demands. For other chronic illnesses, it was the generic symptoms of the illness (e.g. fatigue) that resulted in a work limitation, rather than the specific nature of the illness itself. Employer work adjustments were available to those illnesses which required a physical work adjustment (e.g. musculoskeletal pain). For other chronic illnesses, with the exception of depression, disclosing an illness was the strongest predictor for work adjustments in cognitive tasks and the provision of social support. Those with depression were least likely to receive a cognitive work adjustment, indicating either a low disclosure rate in this group or that employers' perceptions of depression may be a barrier to providing suitable work adjustments.
\end{abstract}

Abstract: 193 words

Main text: 2876 words 


\section{Introduction}

Chronic illnesses are reported to be one of the most prevalent and increasing health problems in both western and developing countries (World Health Organization, 1992). They are represented in a considerable proportion of the working population, particularly older workers (Health and Safety Executive, 2003). Evidence suggests that at least a third of the western economies' workforce is likely to be managing a chronic illness by the age of fifty (Ilmarinen, 1994). Recent studies have reported the adverse outcomes that chronic illnesses have upon workforce participation and performance (Burton et al, 1999; Dewa and Lin, 2000; Kessler et al, 2001; Lerner et al, 2000; Baanders et al, 2002 and Lerner et al, 2003). For example, Burton et al (1999), reported that diabetes and cardiovascular heart disease were associated with high absence from work and low productivity. Kessler et al (2001) found cancer, depression and cardiovascular heart disease to be associated with work limitations (impaired work performance).

Despite these problems, evidence suggests many individuals with chronic illnesses want to remain in active and productive employment (Mancuso et al, 2000). Several authors have suggested that an important indicator for maintaining productive employment is the provision of work adjustments by employers for employees (Daly \& Bound, 1996). However, to date, only a small number of studies has looked at employer work adjustments, and the extent to which such adjustments enable employees to effectively manage their chronic illness and their work (Gulick, 1992; Daly \& Bound, 1996; Mancuso et al, 2000; Baanders et al, 2001). Daly and Bound (1996), and Baanders et al (2001) found that employer work adjustments directly accommodated the work limitations reported by chronically ill employees, enabling them to not only manage their work, but also maintain productive employment (Daly and Bound, 1996). Although these studies found that not all employees reporting a work limitation received work adjustments from their employers, neither study examined possible factors associated with not the failure to receive work adjustments. It is the aim of this paper to investigate this issue. 
The present authors suggest that several factors may account for the discrepancy between work limitations reported and the work adjustments received among chronically ill employees. Firstly, receiving work adjustments from an employer may depend upon whether an employee has disclosed their illness and the effect it has on their work (Munir et al, 2003). This has not been sufficiently examined in studies on work adjustments. Secondly, although Baanders et al (2001) argued in their study that disease diagnosis is not a decisive factor in predicting work adjustments, there is some evidence to suggest that employers make such decisions on the basis of their perceptions and knowledge of certain chronic illnesses, regardless of the general workplace adjustment policies the organisation might have (Glozier, 1998). Therefore, the type of chronic illness should be considered as a separate factor. Thirdly, a large number of individuals manage more than one chronic illnesses and this increases the risks of having a work limitation (Lerner et al, 2000; Kessler, 2001). It may also increase the likelihood of receiving work adjustments, which has not been examined.

In their study, Baanders et al (2001) adopted the work capacity-work load model (Van Dijk et al, 1990) to examine the relationship between specific work limitations and employer work adjustments. In line with Baanders et al study, the authors measured work limitations and work adjustments for three distinct job characteristics: physical work demands, cognitive work demands and social work demands. As there may be more subtle ways in which the provisions of work adjustments are determined, the authors examined the work limitations and the presence of work adjustments associated with eight types of chronic illness. Also examined was the effect of managing multiple illnesses on work limitations and whether disclosure was associated with receiving work adjustments. Further, in order to delineate organisational factors associated with work adjustments, a cross-sectional 'case-control' pilot study was designed, where participants were recruited from the same one large organisation. 


\section{METHOD}

\section{Sample}

The sample is based on cross-sectional data from the first wave (pilot) of the Supporting Employees with Chronic Illness (SECI) study (Munir et al, in press), where all 5,500 employees from a UK University were invited to complete a questionnaire, eliciting information on the nature, impact and management of chronic illness at work. The questionnaire and a letter outlining the general nature and objectives of the study were sent to all employees via the University internal mailing system. All employees were invited to volunteer for the study by completing the questionnaire. A $44 \%$ response rate was achieved for completed returned questionnaires. 734 (34\%) of the respondents declared at least one chronic illness on the questionnaire. The demographic characteristics of the participants are shown in Table 1.

\section{Measures}

The SECI study contains data on chronic illness, health, work characteristics, disclosure, absence, support, work adjustments and future needs or provisions required from the employer. A detailed description of the nature and development of the SECI questionnaire has been provided elsewhere (Munir et al, 2003). Items were constructed following an analysis of published literature on the impact of chronic illness and from semi-structured interviews conducted with a representative sample of 15 employees managing a chronic illness. A draft of the questionnaire was discussed and amended by an expert stakeholder group, and was piloted with a further sample of 15 employees.

\section{Chronic illness and work}

Chronic illness was measured by asking respondents to self-report any chronic illness they currently experienced, and to indicate which condition (if more than one was listed) most affected their work. An explanation of 'chronic illness' was provided with examples (e.g. asthma, diabetes, back pain and arthritis). This measure was developed to be consistent with other self-report measures of chronic illness (Dewa \& Lin, 2000; Lerner et al, 2000). Those respondents with a chronic illness diagnosed by 
a medical practitioner were deemed eligible for inclusion in the study (Dewa \& Lin, 2000). In addition, the questionnaire asked respondents to indicate the severity of their illness (mild, moderate or severe), the frequency of illness-related symptoms experienced (daily, several times a week, once a month, less than once a month) and whether their health condition was characterised by pain or fatigue (not at all, to some extent or to a large extent).

\section{Work limitations}

To assess work limitations, respondents were asked to indicate to what extent they experienced problems at work related to three job characteristics: 1) physical work demands (e.g. completing tasks, mobility; $\alpha$ 0.51), 2) cognitive work demands (such as concentration, memory or problem-solving; $\alpha$ 0.76) and 3) social work demands (dealing with people e.g. colleagues, superiors and clients/students; one item). For each item under the three job categories, respondents were asked to indicate their response on a four point scale from 'all the time' to 'never'. An overall score was then calculated for each job category, where respondents reporting a problem 'all the time' or 'most of the time' for any item within a job category, were classed as having a work limitation within that job category. Respondents reporting a limitation 'some of the time' or 'never' were classed as not having a limitation in that job category and were given a score of 0 . By grouping the 'some of the time' and 'never' responses, a conservative approach to reporting limitations was taken.

\section{Work adjustments}

To assess whether respondents had received any work adjustments to help them overcome their healthrelated problems at work, respondents were asked to indicate if they had received any work adjustment related to three categories: 1) Physical/environmental work adjustments (e.g. lifting, access, reduced work pace or workload, provision of equipment; $\alpha$ 0.95); 2) cognitive work adjustments (e.g. clearer job tasks, different allocation of tasks; $\alpha$ 0.83); and 3) provision of social support (i.e. emotional support, sympathy and understanding from superiors; one item). For each item under the three adjustment categories, respondents were asked to indicate their response on a dichotomous scale (yes or no). 
Respondents indicating a work adjustment on any item listed under a category were classified as having received a work adjustment for that category.

\section{Disclosure}

In order to assess organisational factors associated with the provision of work adjustments, respondents were asked whether they had disclosed the nature of their work limitations associated with their chronic illness to their superiors (e.g. line managers) (yes or no).

\section{Demographics}

Data were collected on participants’ age, gender, occupation and tenure (length of employment).

\section{ANALYSES}

From the 734 reported chronic illnesses, eight illness classifications emerged. Five groups were clearly identified: asthma, arthritis, irritable bowel syndrome, migraine and diabetes (Table 1). For 'depression and anxiety,' participants were grouped if they reported either depression or anxiety, or a combination of both. Two groups were defined using the International Classification of Diseases (ICD 10; World Health Organization, 1999). 'Musculoskeletal pain' referred to participants reporting pain anywhere in the musculoskeletal system (e.g. back, shoulders, neck, arms, elbows, wrist, and lower limbs). For 'heart disease', participants were included if they reported myocardial infarction, angina, heart failure, stroke and hypertension. An additional group, classified as 'Other', represented either smaller numbers of other reported chronic illnesses $(\mathrm{n}=46$ ) or those who reported suffering from musculoskeletal pain for less than three months $(\mathrm{n}=9)$, and from migraine or irritable bowel syndrome for less than 12 months $(n=14)$. This was a conservative measure for self-reported illnesses that might not be chronic (e.g. back strain). A further number of participants $(n=55)$ did not state their illness, and were classified as 'unknown'. In order to make comparisons across the different illness groups, the latter two groups were not included in subsequent analyses (Table 1). The total number of chronic illnesses reported by each respondent was also recorded. 
Due to a high association existing between the 'presence of pain' variable and the chronic illness group 'musculoskeletal pain', the 'presence of pain’ variable was recoded as missing data for this illness group to avoid the occurrence of inflated family wise Type I errors. To determine factors associated with work limitation and work adjustments, two sets of logistic regressions were run for (i) work limitation categories and (ii) work adjustment categories. The first set of logistic regressions modelled the impact of each of the eight chronic illnesses, severity of illness, disease characteristics (i.e. pain and fatigue) and the number of co-existing chronic illnesses on reporting a specific type of work limitation (i.e. physical, cognitive or social). The second set of logistic regressions modelled the impact of work limitations, type of chronic illness, severity of illness, disease characteristics, number of co-existing chronic illnesses and disclosure of chronic illness on the type of work adjustment received. For each set of logistic regressions, data on reported chronic illnesses, the number of chronic illnesses managed and symptoms were entered simultaneously into each logistic regression analysis using a forward inclusion method. Adjustments for demographics were made in order to identify the most important predictors $(p<.05)$

\section{RESULTS}

Table 1 shows the demographic details for participants reporting a particular chronic illness. This was compared with data obtained from the organisation's Human Resources department and indicated that the sample was representative of the population of that organisation in terms of occupational groups, age, gender and tenure. Among those participants included in the analyses $(n=610)$, depression and anxiety were the most frequently reported chronic illness (16.9\%), followed by asthma (13.1\%) and musculoskeletal pain (12.9\%). 
Table 1 Distribution of chronic illnesses and demographic details across participants

\begin{tabular}{|c|c|c|}
\hline \multirow{2}{*}{\multicolumn{3}{|c|}{ Chronic illnesses (n=734) }} \\
\hline & & \\
\hline Depression \& anxiety & 124 & (16.9) \\
\hline Asthma & 96 & (13.1) \\
\hline Musculoskeletal pain & 95 & (12.9) \\
\hline Irritable bowel syndrome & 92 & (12.5) \\
\hline Arthritis & 78 & (10.6) \\
\hline Migraine & 44 & $(6.0)$ \\
\hline Heart disease & 44 & (6.0) \\
\hline Diabetes & 37 & $(5.0)$ \\
\hline Other & 69 & (9.5) \\
\hline Unknown & 55 & $(7.5)$ \\
\hline \multicolumn{3}{|l|}{ Occupational Groupings } \\
\hline Academic & 184 & (25) \\
\hline Clerical/Administration & 175 & (24) \\
\hline Research & 99 & (13) \\
\hline Technical & 97 & (13) \\
\hline Manual & 65 & (9) \\
\hline Academic-related \& Management & 57 & (8) \\
\hline Catering \& Residential Services & 17 & (2) \\
\hline Other & 40 & (6) \\
\hline \multicolumn{3}{|l|}{ Gender } \\
\hline Male & 475 & (65) \\
\hline \multirow[t]{2}{*}{ Female } & 259 & (35) \\
\hline & Mean & SD \\
\hline Age & 42.44 & $(11.02)$ \\
\hline Age at onset & 31.82 & (12.74) \\
\hline No of chronic illnesses managed & 1.34 & $(0.58)$ \\
\hline Tenure (years) & 8.25 & (8.15) \\
\hline
\end{tabular}

Work limitations

Over a third of respondents with a chronic illness (39.7\%; $\mathrm{n}=239)$ reported having a work limitation. Comparing work limitations experienced by the chronic illness groups, depression and anxiety gave the strongest prediction in all three areas of work limitations: physically demanding work ( $(1.22, \mathrm{SE} 0.26)$, cognitively demanding work ( $\beta$ 1.97, SE 0.26 ) and socially demanding work ( $\beta$ 1.92, SE 0.30 ).

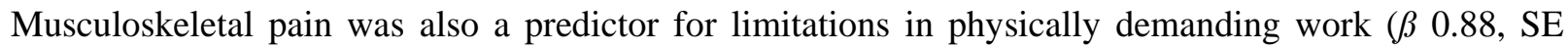


0.32); and migraine and diabetes were significant predictors for limitations in cognitively demanding work ( $\beta$ 1.26, SE 0.40 and $\beta 1.10$, SE 0.44 respectively). For both of these work limitations, a significant effect was also observed for the number of illnesses managed. This indicates that physical or cognitive work limitations incrementally increase with the number of chronic illnesses reported. Additionally, the severity of a chronic illness significantly and independently increased the probability of a work limitation in all three areas. Fatigue associated with chronic illness was a predictor of physically and socially demanding work limitations. When taking into account the effect of chronic illness, severity of illness and disease characteristics, females and academic staff independently were found to report an increased probability of experiencing cognitively demanding work limitations.

TABLE 2: Factors predicting work limitations by employees with chronic illness

\begin{tabular}{|c|c|c|c|c|c|c|}
\hline & \multicolumn{6}{|c|}{ Type of work limitations } \\
\hline & \multicolumn{2}{|c|}{$\begin{array}{l}\text { Physically } \\
\text { Demanding }\end{array}$} & \multicolumn{2}{|c|}{$\begin{array}{l}\text { Cognitively } \\
\text { demanding }\end{array}$} & \multicolumn{2}{|c|}{$\begin{array}{l}\text { Socially } \\
\text { demanding }\end{array}$} \\
\hline & B-coeff. & $(\mathrm{SE})$ & ß-coeff. & $(\mathrm{SE})$ & ß-coeff. & $(\mathrm{SE})$ \\
\hline Depression \& anxiety & 1.22 & $(0.26)$ & 1.97 & $(0.26)$ & 1.92 & $(0.30)$ \\
\hline Asthma & - & & - & & - & \\
\hline Musculoskeletal pain & 0.88 & $(0.32)$ & - & & - & \\
\hline Irritable bowel syndrome & - & & - & & - & \\
\hline Arthritis & - & & - & & - & \\
\hline Migraine & - & & 1.26 & $(0.40)$ & - & \\
\hline Heart disease & - & & - & & - & \\
\hline Diabetes & - & & 1.10 & $(0.44)$ & - & \\
\hline $\begin{array}{l}\text { Number of Chronic illnesses } \\
\text { managed }\end{array}$ & 0.47 & $(0.17)$ & 0.62 & $(0.17)$ & ns & \\
\hline \multicolumn{7}{|l|}{ Severity } \\
\hline Mild (reference category) & 0.00 & & 0.00 & & 0.00 & \\
\hline Moderate & 0.95 & $(0.25)$ & 0.74 & $(0.21)$ & 1.13 & $(0.36)$ \\
\hline Severe & 1.35 & $(0.42)$ & 1.13 & $(0.42)$ & 1.50 & $(0.57)$ \\
\hline Fatigue & 0.74 & $(0.25)$ & ns & & 0.66 & $(0.19)$ \\
\hline Pain & ns & & ns & & ns & \\
\hline Age & ns & & ns & & ns & \\
\hline Age at onset & ns & & ns & & ns & \\
\hline Sex (male) & ns & & -0.54 & $(0.22)$ & ns & \\
\hline Academic & ns & & 0.59 & $(0.23)$ & ns & \\
\hline
\end{tabular}




\section{Work adjustments}

With regards to work adjustments, $30.3 \%(n=185)$ of those with a chronic illness reported receiving work adjustments. Comparing across chronic illness groups, asthma (ß 1.70, SE 0.86), musculoskeletal pain ( $(1.65$, SE 0.34), and arthritis ( $§ 1.35$, SE 0.40 ) were the only predictors of receiving physical work adjustments. For cognitive work adjustments and receiving social support, disclosure of illness to the line manager was the main predictor ( $\beta 0.98$, SE 0.38 and $\beta 2.87$, SE 0.79 , respectively). Those with depression and anxiety however, were significantly less likely to receive cognitive work adjustments. For age at onset of a chronic illness, the probability of receiving social support incrementally decreases with later onset ( $(-0.78$, SE 0.26). There were no other significant effects.

TABLE 3: Factors predicting work adjustments

\begin{tabular}{|c|c|c|c|c|c|c|}
\hline & \multicolumn{6}{|c|}{ Type of work adjustment } \\
\hline & \multicolumn{2}{|c|}{$\begin{array}{c}\text { Physical } \\
\text { adjustments }\end{array}$} & \multicolumn{2}{|c|}{$\begin{array}{l}\text { Cognitive } \\
\text { adjustments }\end{array}$} & \multicolumn{2}{|c|}{ Social suppor } \\
\hline & ß-coeff. & $(\mathrm{SE})$ & B-coeff. & $(\mathrm{SE})$ & B-coeff. & $(\mathrm{SE})$ \\
\hline Depression \& anxiety & - & & -1.35 & $(0.46)$ & - & \\
\hline Asthma & 1.70 & $(0.86)$ & - & & - & \\
\hline Musculoskeletal pain & 1.65 & $(0.34)$ & - & & - & \\
\hline Irritable bowel syndrome & - & & - & & - & \\
\hline Arthritis & 1.35 & $(0.40)$ & - & & - & \\
\hline Migraine & - & & - & & - & \\
\hline Heart disease & - & & - & & - & \\
\hline Diabetes & - & & - & & - & \\
\hline $\begin{array}{l}\text { Number of Chronic illnesses } \\
\text { managed }\end{array}$ & ns & & ns & & ns & \\
\hline Disclosure of illness to line manager & ns & & 0.98 & $(0.38)$ & 2.87 & $(0.79)$ \\
\hline Age & ns & & ns & & ns & \\
\hline Age at onset & ns & & ns & & -0.78 & $(0.26)$ \\
\hline Sex & ns & & ns & & ns & \\
\hline
\end{tabular}




\section{DISCUSSION}

The results of this study contribute toward an understanding of specific work limitations associated with chronic illnesses and the type of work adjustments received. The study extends the work of Baanders et al (2001), by exploring the effect of managing particular chronic illnesses, multiple illnesses and the incidence of disclosure on receiving work adjustments. In this study, almost $40 \%$ of the sample reported a current work limitation. This is comparable to Lerner et al's (2000) national household study on chronically ill employees which reports a $32.4 \%$ prevalence rate.

The present study is also consistent with the extant literature in finding depression to have the largest impact on all three areas of work demands; migraine and diabetes on cognitive work demands; and musculoskeletal pain on physical work demands (Burton et al 1999; Lerner et al, 2000; Dewa \& Lin, 2000; Kessler et al, 2001). For other illnesses, severity and fatigue associated with the illness were the strongest predictors of physically and socially demanding work limitations. The results suggest that for some chronic illnesses (e.g. depression and diabetes), the specific nature of the illness affects work performance. For other chronic illnesses (e.g. irritable bowel syndrome), the results suggest that it is the more generic disease characteristics that affect work performance. The risks associated with the total number of chronic illnesses managed was also significant, indicating that multiple concurrent illnesses may present a fuller range of work limitations which require work adjustments.

Over $30 \%$ of the sample reported receiving some kind of work adjustment. This is somewhat higher than Baanders et al (2001) national study, which reported a $15.7 \%$ work adjustment rate, but comparable to Daly and Bound's (1996) national study, which reported a 29.2\% prevalence for work adjustments. In this study, generic disease characteristics such as the severity of illness and fatigue, were not found to be predictors of work adjustments. Instead, the strongest predictors were musculoskeletal pain, arthritis and asthma for physical work adjustments, followed by the disclosure of chronic illness to a line manager for cognitive work adjustments and social support. These results indicate that as physical work adjustments are tangible, they are perhaps easily identified and made 
available to employees early (for example, the use of lifting equipment, wrist rests, training in handling and lifting).

For cognitive work adjustments and social support, the results suggest that unless disclosure of a chronic illness takes place, work adjustments are unlikely to be received. However, those with depression seem to be an exception as they are less likely to receive a cognitive work adjustment despite disclosure. There are several implications for this finding. Firstly, line managers may not be fully aware of the nature of depression and its impact on work performance, even when an employee discloses his/her illness. Secondly, evidence suggests that depression is generally perceived to be a stigmatising condition (Glozier, 1998), a perception possibly shared by line managers or by the organisation itself. Thirdly, employees with depression are perhaps less likely to disclose their illness either because of perceived discrimination, stigmatisation or due to the nature of the illness itself. Finally, the number of chronic illnesses managed was not a significant predictor for work adjustments. This indicates that employees are perhaps disclosing only one (primary) chronic illness to access work adjustments.

The findings from this study suggest that disclosure of chronic illness is an important predictor of work adjustments. Unless employees' choose to disclose their illness, access to work adjustments may be lacking. However, the choice to disclose is complex and may be influenced by stigma, type, severity of illness and perceived organisational support (Vickers, 1997; Munir et al, in press). This is an area that needs further exploration. Recent developments in European and national legislation outline the need to promote the participation of people with illness and disabilities in the workforce (e.g. EU Council Directive 2000/78/EC). Much of this attention will focus on discrimination in various human resource practices (e.g. recruitment, selection, training, promotion etc). Further studies are required to address organisational perceptions of chronic illness as employers play an important role in protecting this sizeable group of the labour force from reduced participation and performance. 


\section{REFERENCES}

Baanders, A. N., Andries, F., Rijken, P. M., \& Dekker, J. (2001). Work adjustments among the chronically ill. International Journal of Rehabilitation Research 24, 7-14.

Baanders A.N., Rijken, P.M., \& Peters, L. (2002). Labour force participation of the chronically ill- A profile sketch. European Journal of Public Health 12 (2), 124-130.

Burton, W. N., Conti, D. J., Chen, C-Y., Schultz, A. B., Edington, D. W. (1999). The role of health risk factors and disease on worker productivity. Journal of Occupational Environmental Medicine $\mathbf{4 1}$ (10), 863-877.

Daly, M. C., \& Bound, J. (1996). Worker adaptation and employer accommodation following the onset of a health impairment. Journal of Gerontology, 51B (2) S53-S60.

Dewa, C. S., \& Lin, E. (2000). Chronic physical illness, psychiatric disorder and disability in the workplace. Social Science \& Medicine 51, 41-50.

Gulick, E. E. (1992). Model for predicting work performance among persons with multiple sclerosis. Nursing Research 41 (5), 266-272.

Glozier, N. (1998). Workplace effects of stigmatisation of depression. Journal of Occupational Environmental Medicine 40 (9), 793-800.

Health \& Safety Executive (2003). Self-reported work-related illness 2001/2002. http://www.hse.gov.uk/statistics.

Ilmarinen J. (1994) Ageing, work and health. In: J Snel \& R. Cremer (Eds.), Work and ageing: A European perspective. London: Taylor \& Francis.

Kessler, R.C., Greenberg, P.E., Mickelson, K.D., \& Wang, P.S. (2001). The effects of chronic medical conditions on work loss and work cutback. Journal of Occupational and Environmental Medicine 43, 218-225. 
Lerner, D., Amick, B. C., Malspeis S., \& Rogers, W. H. (2000). A national survey of health-related work limitations among employed persons in the United States. Disability and Rehabilitation 22, 225232.

Lerner, D., Amick, B. C., Lee, J. C., Rooney, T., Rogers, W. H., Chang, H., Berndt, E. R. (2003).

Relationship of employee-reported work limitations to work productivity. Medical Care 41 (5), 649659.

Mancuso, C. L., Paget, S. T., \& Charlson, M. E. (2000). Adaptations made by rheumatoid arthritis patients to continue working: a pilot study of workplace challenges and successful adaptations. Arthritis Care and Research 13, 89-99.

Munir, F., Leka, S., \& Griffiths, A. (2003). Management of work-related and non work-related chronic illnesses at work. In S. Giga, P. Flaxman, J. Houdmont, \& M. Ertel (Eds). Occupational Health Psychology: Flexibility, quality of working life and health. European Academy of Occupational Health Psychology Conference Proceedings Series. Berlin: BAuA.

Munir, F., Leka, S., \& Griffiths, G. (in press). Dealing with self-management of chronic illness at work: predictors for self-disclosure. Social Science \& Medicine.

Van Dijk, F.J.H., Van Dormolen, M., and Kompier, M. A. J. (1990). Revaluation of the work load work capacity model (Herwaardering model belasting-be-lastbaarheid). Tijdschrift Sociale Gezondheidszorg 68, 3-10.

Vickers, M. (1997). Life at work with ‘invisible’ chronic illness (ICI): The ‘unseen’, unspoken, unrecognised dilemma of disclosure. Journal of Workplace Learning 7, 240-252.

World Health Organization (1992). Health promotion and chronic diseases: Discovering a new quality of health. Copenhagen: World Health Organization Regional Office for Europe.

World Health Organization (1999). International Classification of Diseases - Version 10. Geneva: World Health Organization 